Historic, Archive Document

Do not assume content reflects current scientific knowledge, policies, or practices. 



\section{A Multiple BAF Angle Gage}

Peter F. Ffolliott ${ }^{1}$

This Note describes the construction of an intercept angle gage ${ }^{2}$ that allows a choice of different basal area factors (BAF's) in point-sampling, and automatically corrects for slope (fig. 1). It is simple to construct and inexpensive.

A sighting angle or critical angle is established, corresponding to a given basal area factor, by placing a crossarm of a known width on a rod of a known length. The angle gage described here has individual crossarms of different widths for different basal area factors. All crossarms are used with a rod of a constant length. Simply changing crossarms allows point sampling with any basal area factor desired. The crossarms, which swing freely when the rod is inclined, rotate around the line of sight by an amount equal to the slope, thereby automatically compensating for slope. ${ }^{3}$

$1_{\text {Associate Sizviculturist, rocated at }}$ Flagstaff, in cooperation with Arizona State College; central headquarters are maintained at Fort Collins, in cooperation with Colorado State University.

${ }^{2}$ Grosenbaugh, L. R. Point-sampling and line sampling: probability theory, geometric implications, synthesis. U. S. Forest Serv. South. Forest Expt. Sta. Occas. Poper 160, 34 pp. 1958.

${ }^{3}$ BeZl, J. R., and Alexander, L. B. Applications of the variable plot method of sampling forest stands. Ore. State $B d$. Forestry Res. Note 30, 22 pp. 1957.
A straight-grained piece of hardwood (maple, ash, or other type) $3 / 4$ inch by $1-1 / 4$ inches by approximately 32 inches serves as the rod. A crossarm holder is attached to one end of the rod (fig. 2a). The distance from the notch in the crossarm holder to the opposite end of the rod is 30 inches. The crossarm holder is made from a piece of metal $3 / 8$ inch by $1-1 / 4$ inches by $3-1 / 2$ inches (fig. $2 b$ ). A

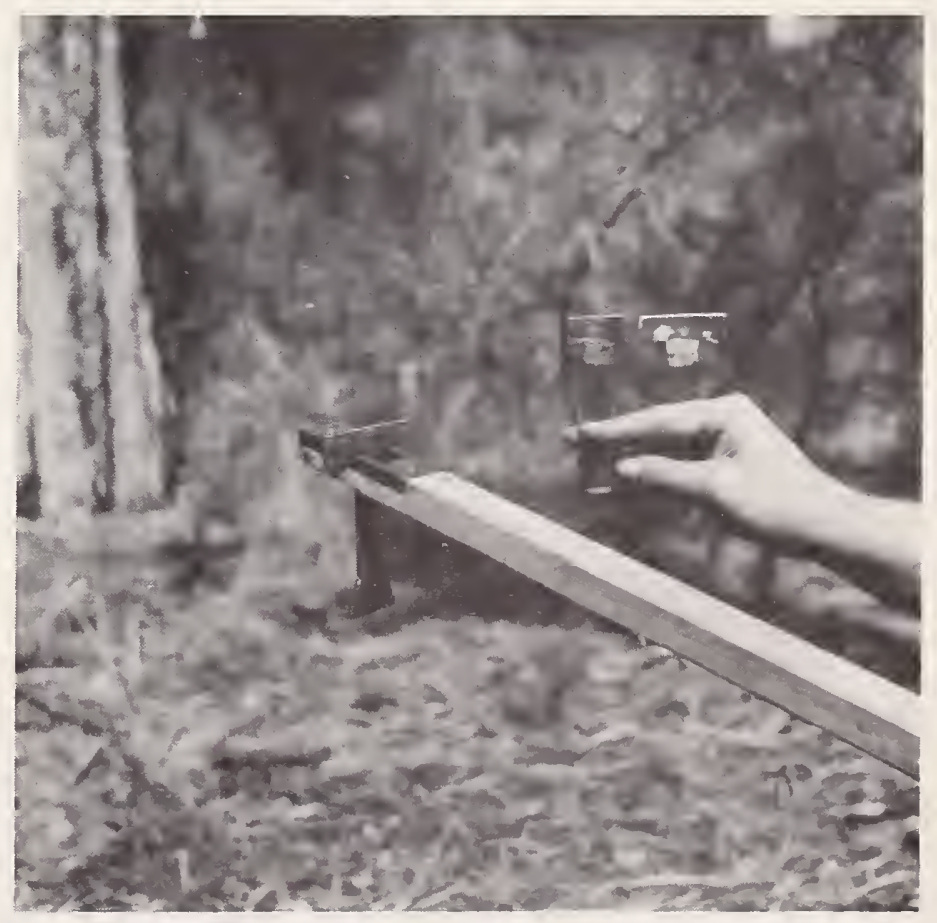

Figure 1.--A multiple BAF congle gage. 
slot $7 / 8$ inch by $1-1 / 2$ inches, cut in the center of the crossarm holder and in the rod beneath the crossarm holder, allows the crossarm to swing freely when in place (fig. 2c).

The material used in making the crossarms can be any heavy metal not exceeding $1 / 8$ inch in thickness. Each crossarm has a

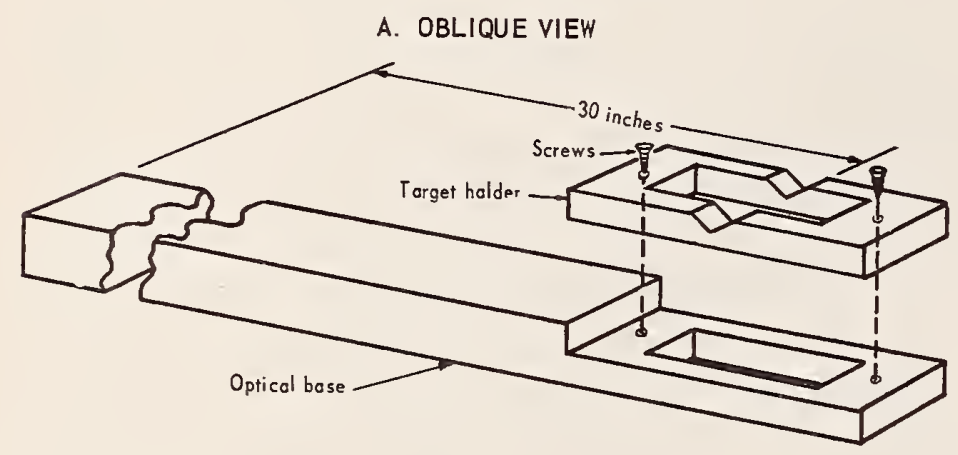

B. TARGET HOLDER
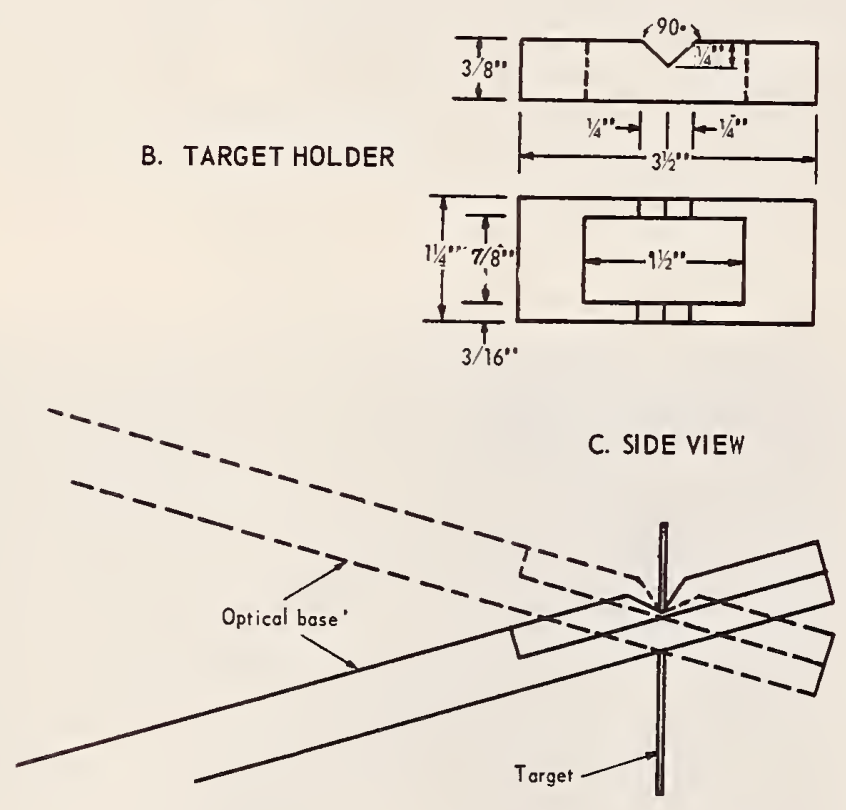

Figure 2.--A. Crossarm holder is attached to the rod with notch of crossarm holder 30 inches from opposite end of rod (dimensions in inches). B. Crossarm holder design for murtiple BAF angle gage (dimensions in inches). C. Crossarm swings freely when rod is incline $\bar{d}$.

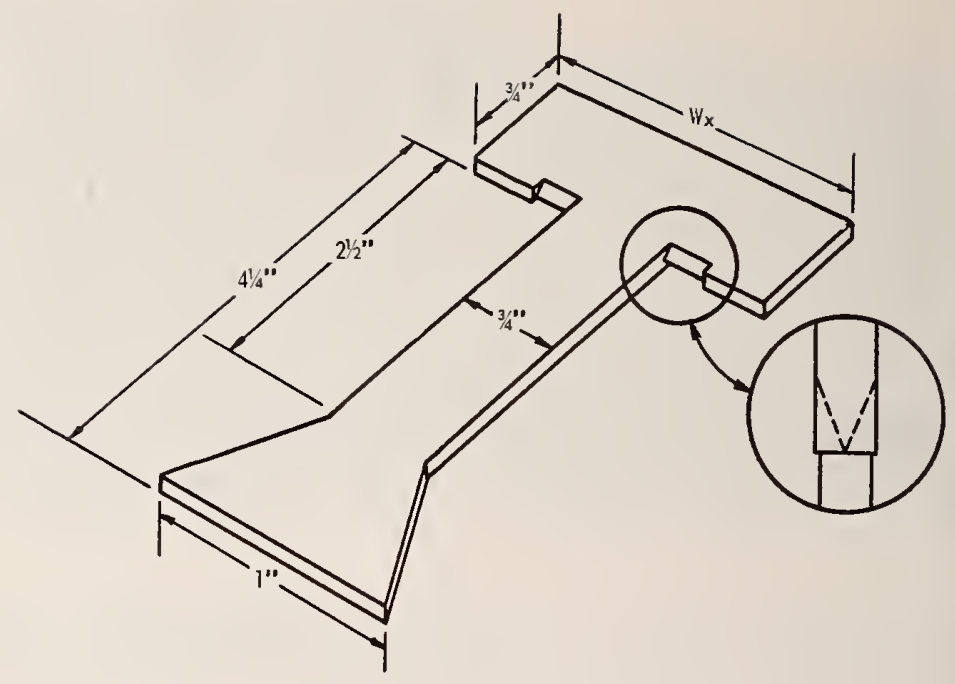

Figure 3.--Crossarm design for multiple BAF angle gage. The width of sight blade will vary with basal area factor (dimensions in inches).

sight blade and a base (fig. 3 ). The width of the sight blade, which determines the basal area factor, is obtained from the relationship: width (inches) $=$ crossarm length factor $X$ $\times 30$ (inches).

Common crossarm length factors can be determined for different basal area factors by the equation:

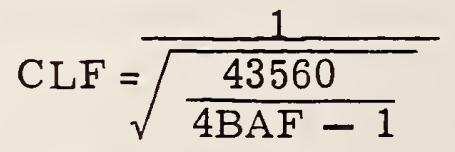

where

CLF $=$ crossarm length factor

$\mathrm{BAF}=$ basal area factor

Grosenbaugh ${ }^{4}$ gives crossarm length factors for commonly used basal area factors. The dimensions of the base of each crossarm are the same (fig. 3 ). The base acts as a pendulum, insuring free movement of the crossarm when the rod is inclined (fig. 2c).

Biltmore and hypsometer graduations can be stamped on the rod to provide an allpurpose cruising instrument.

${ }^{4}$ Grosenbaugh, L. R. Better diagnosis and prescription in southern forest management. U. S. Forest Serv. South. Forest Expt. Sta. Occas. Poper 145, 27 pp. 1955. 